\title{
Vulnerabilidade, reconhecimento e saúde da pessoa idosa: autonomia intersubjetiva e justiça social*
}

\author{
Vulnerability, recognition and health in old age: intersubjective autonomy and social \\ justice
}

Aluisio Almeida Schumacher' ${ }^{1}$, Rodolfo Franco Puttini², Toshio Nojimoto3,

'Doutor em Ciências Sociais pela Universidade Estadual de Campinas (Unicamp) - Campinas (SP), Brasil. Professo Adjunto da Universidade Estadual Paulista (UNESP) - São Paulo (SP), Brasil. aluisioschumacher@yahoocombr

${ }^{2}$ Doutor em Saúde Coletiva pela Universidade Estadual de Campinas (Unicamp) - Campinas (SP), Brasil. Professor Assistente da Universidade Estadual Paulista (UNESP) -Botucatu (SP), Brasil. puttini@fmb.unesp.br

${ }^{3}$ Doutor em Economia pela Universidade de São Paulo (USP) - São Paulo (SP), Brasil. Professor Titular da Universidade Estadual Paulista (UNESP) -Botucatu (SP), Brasil. toshio@fca.unesp.br
RESUMO Os idosos são objeto de políticas públicas de proteção contra riscos e doenças. Pelo pressuposto liberal, a questão é tornar o indivíduo independente, o que contribui para isolar e fragilizar o idoso. Propomos o paradigma do reconhecimento e os vínculos sociais, apoiando a vida de sujeitos que reconhecem e são reconhecidos. A autonomia intersubjetiva é garantida por relações de afeto/amizade, estima social, reconhecimento de direitos e responsabilidades, e ameaçada pela desvalorização, por desrespeito e violências. Isso contribui trazendo a compreensão de fenômenos de desrespeito, difamação e traumas, e apoiando a instituição de cuidados com vistas à integridade e à justiça social.

PALAVRAS CHAVE: Reconhecimento social; autonomia intersubjetiva; vulnerabilidade em saúde; saúde do idoso; justiça social.

ABSTRACT The elderly are the object of policies of protection against risks and diseases. According to the liberal premise, the idea is ensure the individual's independence, which actually serves to isolating and weakening the elderly. We propose the paradigm of recognition and social bonds that support the life of individuals who exercise recognition and are recognized. Intersubjective autonomy is guaranteed through relations of affection/friendship, social esteem, recognition of rights and responsibilities and threatened by de-valuing attitudes, disrespect and violence. This contributes to the health of the elderly, by understanding exclusion, slander and trauma and supporting the care institution with a view to integrity and social justice.

KEYWORDS: Social recognition; Intersubjective autonomy; Vulnerability in health; Health in old age; Social justice.

* As primeiras seções deste artigo retomam, com modificações, partes do trabalho apresentado no V International Congress of Qualitative Inquiry, em Urbana, Illinois (EUA), em 2009 (SCHUMACHER et al., 2009). Os autores agradecem o apoio da FAPESP. 


\section{Introdução}

Somente por volta dos anos 1950, a visão redutora, que toma as características físicas, mentais e sociais do envelhecimento como exclusivamente naturais e, em larga medida, inevitáveis, começa a ser revista. Desde então, predomina, pelo lado do envolvimento com as instituiçôes sociais e da perspectiva da construção do conhecimento sobre a condição da pessoa idosa, nítida tendência a pressupor, nas explicaçóes e propostas de políticas públicas, que se está lidando com indivíduos isolados.

É claro, a própria estruturação da sociedade induz a isso (TOWNSEND, 1980): há a imposição (e aceitação) de aposentadorias precoces, a legitimação de baixas rendas, a negação do direito à autodeterminação em instituições, assim como a construção de serviços de apoio e cuidado supondo idosos (as) completamente passivos (as). Todos esses fatores contribuem para negar às pessoas idosas possibilidades de desenvolverem interaçôes sociais em condiçóes de autonomia e igualdade, diminuindo suas possibilidades de desenvolverem uma vida social dinâmica, afetando, assim, sua saúde.

Pelo lado das Ciências Sociais, as explicaçóes sobre o envelhecimento do indivíduo na sociedade se inspiram, em geral, em enfoques neoclássicos em economia e em tradiçóes funcionalistas em sociologia (TIBBITTS, 1960; ATCHLEY; SELTZER, 1976; STEARNS, 1977; CLARK; SPENGLER, 1980), orientando políticas públicas de cunho liberal. Essas abordagens não se preocupam em compreender os elementos que restringem as oportunidades de vida para idosos. Em vez disso, dirigem sua atenção, principalmente, à questão de como adaptá-los à estrutura social, o que, em última instância, contribui para legitimar o estado de coisas existente.

Pelo lado da medicina, o discurso médico e paramédico, que orienta os cuidados gerontológicos e geriátricos aos idosos, mantém a dominância de uma linguagem técnica e especializada que nem sempre oferece a possibilidade de apreensão crítica do contexto social (WAITZKIN, 1989; EAKIN et al, 1996). O modelo que emerge do discurso médico se caracteriza pela ênfase no (a) cuidador (a), o (a) verdadeiro (a) conhecedor (a) do problema em face de um (a) paciente que ignoraria os cuidados e procedimentos mais elementares. Não é difícil depreender, daí, uma tendência à medicalização dos problemas das pessoas idosas, em detrimento de aspectos vinculados às vidas social e mental (TESSER, 2006).

Considerado um grupo social em situação de vulnerabilidade ${ }^{1}$, a população idosa é objeto de políticas públicas que visam a protegê-la dos riscos inerentes ao envelhecimento, garantindo sua autonomia. Tal autonomia é concebida de modo individualista, como se a questão fosse tornar a pessoa idosa o mais independente possível de seu entorno social. Ora, combinada ao modo de estruturação da sociedade, ao envolvimento com as instituiçôes sociais e ao tipo de explicação dos profissionais de saúde para a condição da pessoa idosa, essa ênfase individualista nas políticas públicas acaba contribuindo para isolar e excluir mais ainda esse grupo social.

Propomos uma maneira diferente de compreender e agir com relação ao problema da pessoa idosa na sociedade. Pretendemos fazê-lo recorrendo ao paradigma do reconhecimento, que orienta conhecimento e ação de modo distinto do enfoque individualista ou liberal. No modelo proposto, a forma de autonomia é intersubjetiva, ou seja, é assegurada por relaçóes sociais de reconhecimento em que sujeitos reconhecem e são reconhecidos. No contexto dessa concepção de autonomia, nossa atenção se dirige às relaçôes sociais que suportam a autonomia do indivíduo na sociedade e aos fatores que podem restringi-la. A autonomia intersubjetiva é garantida por uma rede de relaçóes sociais de afeto/amizade, estima social, reconhecimento de direitos e responsabilidades. E ameaçada ou rompida por atitudes de desvalorização (difamação ou humilhação); desrespeito (subordinação, marginalização e exclusão); e por violências (traumas). Entendemos, assim, que o paradigma do reconhecimento contribui para uma melhor compreensão das condições sociais de integração

1 Podemos entender por vulnerabilidade o grau em que a situação social de uma pessoa a deixa susceptível ao desrespeito, difamação ou violência, relacionados à vida moral ou à própria saúde, conforme explicitamos no final do artigo. 
da pessoa idosa na sociedade, fundamentais para a manutenção da saúde e para evitar fenômenos de desorientaçáo na vida social cotidiana.

O argumento está organizado em quatro seçóes. Inicialmente, apresentamos um breve esboço da teoria do reconhecimento social, de Axel Honneth (2003), o fundamento teórico-normativo da abordagem proposta. Na segunda seção, confrontamos a concepção liberal e dominante de autonomia com a autonomia intersubjetiva, precisando, assim, nosso enfoque. Na terceira, explicamos como as três formas de reconhecimento social asseguram a autonomia intersubjetiva (apoiada em sentimentos de autoconfiança, autorrespeito e autoestima) e os fatores que a rompem, em cada uma das três dimensões. Na última seção, procuramos mostrar afinidades entre reconhecimento social, autonomia intersubjetiva e uma visão integrada sobre vida, saúde e doença, e suas relaçóes com o meio, inspirada em Canguilhem (1979). Consideramos que tal orientação reúne elementos que permitem compreender melhor a vulnerabilidade social da pessoa idosa e os cuidados que tal condição demanda em nossas sociedades.

\section{Aspectos centrais da teoria do reconheci- mento social}

Em sua teoria do reconhecimento social, Axel Honneth (2003) - pensador social vinculado à teoria crítica da sociedade, na tradição de Horkheimer (1975) e Habermas $(1988)^{2}$ - trata de explicar a interconexão entre: (a) três estágios de desenvolvimento da 'formação da identidade' individual (aspecto normativo); (b) três 'formas de reconhecimento's intersubjetivo requeridas para cada estágio (aspecto prático); e (c) as 'formas de organização social', entendidas como pré-condições para a autorrealização saudável e não distorcida da vida dos membros da sociedade.

Em contraposição com essas pré-condições para a autorrealização saudável, Honneth (2003) concebe 'formas de desrespeito' ou rupturas (aspecto explicativo) que violam as três formas de reconhecimento. A interconexão proposta lança as bases para explicar processos de mudança social a partir de impulsos para expansão do reconhecimento e de suas respectivas pretensōes normativas, levantadas pelos agentes nas lutas sociais por reconhecimento individual e de grupo.

Com base no trabalho do jovem Hegel (período de Jena) e na psicologia social de George Herbert Mead (1950), Honneth (2003, p. 29-117) explica a 'formação da identidade' como um processo intersubjetivo e constante de luta por reconhecimento mútuo entre parceiros de interação. Por meio desse processo, os indivíduos desenvolvem três formas de relação consigo mesmo, através de três tipos diferentes de interação social: a 'autoconfiança' é adquirida em relaçóes afetivas, o 'autorrespeito' em relaçóes jurídicas de direitos e a 'autoestima' em comunidades locais definidas por orientaçóes de valor compartilhadas. Esses processos intersubjetivos de aprendizagem - de ver-se a si mesmo da perspectiva normativa dos parceiros de interação - constituem as mediações por meio das quais os indivíduos se tornam o que são. É também no interior desses processos intersubjetivos que formas sociais de vida são, continuamente, sustentadas e reproduzidas.

Quanto às 'formas de reconhecimento', Honneth (2003, p.117-213) esclarece que a primeira e mais básica é a que se realiza nas relaçóes íntimas de amor

\footnotetext{
${ }^{2}$ Costuma-se dizer que uma teoria social é crítica quando procura promover a emancipação humana, ou seja, tem o interesse implícito de libertar os agentes sociais das circunstâncias que os dominam e escravizam. Tendo em vista esse objetivo, teorias críticas procuram reunir bases descritivas e normativas em pesquisa social, dirigidas de modo a combater a dominação e incrementar a liberdade em todas as suas formas. O termo é empregado articuladamente pela primeira vez por Horkheimer (1975), em 1937, ao examinar as raízes da moderna concepção de ciência, com o objetivo de reunir elementos para fundamentar a teoria crítica enquanto expressão da autoconsciência dos processos de emancipação social e política, no contexto prático então visível. Jürgen Habermas (1987) foi assistente de Adorno, talvez o principal expoente da primeira geração da teoria crítica, e é o principal representante da segunda geração. Após compartilhar das análises da geração anterior até o final dos anos sessenta, passou a olhar com desconfiança para seus fundamentos normativos, formulando uma teoria da ação comunicativa e deslocando a ênfase do paradigma da consciência para o da comunicação (intersubjetiva). Axel Honneth foi assistente de Habermas e é o principal nome da terceira geração da teoria crítica. Através da categoria do reconhecimento, reintroduziu na tradição crítica a dimensão do conflito e sua importância na ordem social.

${ }^{3}$ Mesmo sendo tão antigo quanto a reflexão filosófica, o uso atual do conceito de reconhecimento aparece nos últimos vinte anos, a partir dos debates políticos e da luta dos movimentos sociais por consideração. O debate em torno do multiculturalismo e a autocompreensão teórica, desenvolvida pelo movimento feminista, colocaram em evidência uma ideia normativa comum: de que os indivíduos e grupos sociais necessitam de reconhecimento ou respeito em sua diferença (TAYLOR, 1992). Desenvolveu-se, então, a convicção de que a qualidade moral das relações sociais não se esgota na justa distribuição de bens materiais. Na verdade, a ultrapassa, na medida em que nossa noção de justiça compreende, também, a maneira como os sujeitos sociais se reconhecem reciprocamente..
} 
e amizade. Por meio dessas relaçóes, os indivíduos se tornam capazes de conceber graus de confiança neles mesmos distintos do ambiente e do mundo circundante. Para desenvolver 'autoconfiança', estabilizando sua identidade e o mundo lá fora, as crianças necessitam de reconhecimento e apoio contínuos através de relaçóes emocionais, proporcionando uma realidade estável que lhes permita vencer suas relaçoos inicialmente simbióticas e indiferenciadas com os outros de referência.

A segunda forma de reconhecimento se dá por meio do conhecimento que o indivíduo adquire acerca de sua capacidade formal para ação moral autônoma. Através dos direitos universais conferidos a todos os membros da sociedade, os indivíduos se tornam capazes de se autorrespeitar, isto é, de se considerarem iguais aos outros, com direito de tomar decisóes, conceber e desenvolver planos de vida próprios. Essa segunda forma de relação consigo mesmo, o 'autorrespeito', se realiza por meio de relaçóes jurídicas que reconhecem cada um como igualmente merecedor de direitos a liberdades negativas $^{4}$, de acesso a processos políticos e, como contrapartida, dotado de responsabilidade jurídica.

A terceira forma de reconhecimento deriva da participação de cada um em contribuição positiva para uma forma de vida compartilhada, que expressa valores específicos, mantidos de modo comunitário. Em um grupo definido pela solidariedade social (menor do que o grupo de cidadãos no qual se realiza o autorrespeito), o indivíduo é capaz de adquirir 'autoestima' ao ser reconhecido como distinto dos outros, mas com particularidades e habilidades que contribuem positivamente para projetos compartilhados de uma comunidade nucleada pela solidariedade.

Em nossas sociedades modernas, essa terceira forma de relação consigo mesmo é distinta - e deve ser diferenciada - da segunda forma de autorrespeito. Isso porque as relaçóes jurídicas devem reconhecer em todos os cidadãos as características abstratas da autonomia moral em igualdade de condiçóes, enquanto o processo de estimar uma pessoa coloca em cena a questão de seus traços mais específicos, positivamente avaliados no interior de uma comunidade que compartilha determinado horizonte de valores. Assim, enquanto a autoconfiança e a autoestima envolvem a compreensão que cada um tem de si em sua concreta particularidade, o autorrespeito envolve a relação de cada um consigo em sua abstrata universalidade.

Com o objetivo de explicar lutas históricas por reconhecimento, Honneth (2003, p. 213-253) faz corresponder às três formas positivas três 'formas de desrespeito' ou ruptura nas relações de reconhecimento. Mostra que experiências de desrespeito podem servir como motivação moral para a luta de indivíduos e grupos pela expansão de relaçóes de reconhecimento, quando enfatizam os defeitos em arranjos sociais existentes. No nível mais fundamental, quando o controle do indivíduo sobre seu corpo - sua integridade física - é violado por violência física, tortura, etc., então, o indivíduo perde a confiança na estabilidade de sua identidade básica e a constância de seu mundo, sentimentos interiores necessários para um sentido saudável de 'autoconfiança'. Em segundo lugar, o 'autorrespeito' moral de um indivíduo pode ser negativamente afetado com a negação sistemática de direitos outorgados a outros cidadãos formalmente iguais. Finalmente, a 'autoestima' de um indivíduo pode ser abalada pela difamação e/ou degradação de seu modo de vida, quando esse não recebe a estima social necessária para uma compreensão saudável de suas capacidades e realizaçóes específicas.

Com base na estrutura que compreende três formas de reconhecimento e três formas correspondentes de desrespeito, podemos retirar três diferentes tipos de pretensões morais, isto é, pretensóes de ser reconhecido como a pessoa autônoma e única que cada um é. Nesse contexto, o comportamento desrespeitoso significa injustiça não só porque fere os agentes ou restringe sua liberdade de agir, mas porque os injuria em sua própria compreensão positiva, intersubjetivamente adquirida.

Assim, às rupturas sociais nas relaçóes de reconhecimento correspondem violaçóes de pretensóes morais

${ }^{4}$ As liberdades negativas do indivíduo correspondem às liberdades (ou direitos) civis: direitos à vida, à liberdade, à propriedade, à igualdade perante a lei; garantias de ir e vir, de escolher o trabalho, de manifestar o pensamento, de organizar-se, de ter respeitada a inviolabilidade do lar e da correspondência, de não ser preso a não ser pela autoridade competente e de acordo com as leis, de não ser condenado sem processo legal regular. 
implícitas, levantadas quando indivíduos e grupos lutam para vencer rupturas percebidas nas diferentes formas de reconhecimento (ANDERSON; HONNETH, 2005, p. 132). Quando experiências individuais de desrespeito são compreendidas como norma por todos os membros de certo grupo - ou quando são vivenciadas como uma epidemia -, existe motivação potencial para resistência política coletiva às estruturas da sociedade, que nega sistematicamente aos membros daquele grupo o reconhecimento de que necessitam para sua autorrealização.

\section{Individualismo (liberal), direitos sociais e au- tonomia intersubjetiva}

Do ponto de vista histórico, a modernidade ocidental significa a emergência de concepçóes de liberdade e autonomia que marcam nossa compreensão contemporânea de justiça social. Concomitantemente ao processo de libertação dos indivíduos das amarras religiosas e da tradição, possibilitando que orientem suas vidas segundo caminhos próprios, configurou-se uma tendência a equiparar liberdade e autonomia pessoais com a permissão concedida aos indivíduos para desenvolverem seus fins sem qualquer tipo de constrangimento por parte dos outros.

Para Anderson e Honneth (2005, p. 128), essa concepção moderna de autonomia traz consigo um componente adicional: a ideia de que os indivíduos realizam sua autonomia ganhando independência de seus coassociados. Isso para não falar das leituras que tornam a autonomia equivalente ao isolamento. $\mathrm{Na}$ dimensão da justiça social, essa tendência se traduz, muitas vezes, na defesa da visão de que criar uma sociedade justa é tornar as pessoas o menos dependentes possível umas das outras. As consequências conceituais dessa ênfase individualista são importantes: além da ideia de que a autonomia cresce com a riqueza, também a noção de que pertencer a uma comunidade sem optar explicitamente por ela representa ameaça à autonomia pessoal.

Esse foco nas liberdades negativas do indivíduo "parece repousar na idealização desorientadora de um indivíduo autossuficiente e autoconfiante"
(ANDERSON; HONNETH, 2005, p. 129). Ao retirar de cena a possibilidade de interferência, tal foco desconsidera requisitos de justiça social, falhando em apreender adequadamente as necessidades, vulnerabilidades e a interdependência entre os indivíduos. Se considerarmos que as pessoas (inclusive as autônomas) são muito mais vulneráveis e interdependentes do que o modelo liberal dá a entender, então podemos ter acesso a um quadro bem diferente acerca dos requisitos para promoção da justiça social.

A constatação de que a autonomia pessoal requer recursos e circunstâncias que tornem o indivíduo capaz de levar a vida que considera digna ganha um primeiro impulso com a institucionalização dos direitos sociais: direitos de participação na riqueza coletiva, incluindo direito à educação, ao trabalho, ao salário justo, à saúde etc. A instituição dos direitos sociais desloca a atenção exclusiva nas liberdades negativas em direção a uma concepção mais positiva e material dos direitos. Incorpora-se, assim, a ideia de que reforçar a autonomia, especialmente a dos vulneráveis, envolve um compromisso, vinculado à justiça social, de garantir as condiçóes materiais e institucionais da autonomia. Fraser (1996, p. 30-31) denomina tais condições de objetivas, demonstrando que a distribuição de recursos materiais tem de se processar de modo a garantir aos participantes da vida social independência e 'voz'.

Sem menosprezar a importância das condiçóes objetivas, estamos, principalmente, preocupados com o que podemos chamar de condiçóes intersubjetivas da participação autônoma na vida social (FRASER, 1996, p. 31): a institucionalização de padróes culturais de interpretação e avaliação que expressem igual respeito por todos os participantes. Essa condição exclui padróes culturais que depreciem, sistematicamente, algumas categorias de pessoas e suas diferenças, deixando de reconhecê-las. Nesse contexto, emerge uma concepção de autonomia que denominamos intersubjetiva, social ou derivada do reconhecimento (NEDELSKY, 1989): a "autonomia que só existe no contexto de relaçóes sociais que a suportam e em conjunção com o sentimento interno de se sentir autônomo".

É claro, e não pretendemos negá-lo, essa forma de autonomia envolve condições objetivas de existência 
social, mas é garantida por um sentimento interno que a própria pessoa desenvolve em conjunção com relaçôes sociais de reconhecimento nas dimensôes do afeto/amizade/cuidado, da estima social e do reconhecimento pelos parceiros de que se trata de um agente responsável. Introduzimos tal tipo de autonomia para compreender as condiçóes intersubjetivas da vida social da pessoa idosa, porque entendemos que certas vulnerabilidades derivadas do envelhecimento na sociedade não são nem mesmo apreendidas pelas concepçôes de justiça social, orientadas, exclusivamente, pelas condiçôes materiais e institucionais da autonomia.

$\mathrm{Na}$ verdade, é porque o processo de envelhecimento coloca, efetivamente, limitações nas condiçôes objetivas de autonomia das pessoas idosas (dificuldades provenientes, principalmente, de condiçóes de saúde) que insistimos na importância das condiçôes intersubjetivas da autonomia como elementos decisivos para que as pessoas idosas possam se autorrealizar socialmente e desenvolver um modo digno e orientado de vida social, contribuindo com sua experiência. Pretendemos também que nossa leitura contribua para a formulação de políticas públicas e cuidados que considerem a importância da dimensáo do reconhecimento enquanto elemento passível de contribuir para uma integração moralmente saudável da pessoa idosa à sociedade, de modo, inclusive, a enfrentar fenômenos de desorientação mental. Nos próximos parágrafos, vamos tratar de detalhar esse enfoque.

$\mathrm{Na}$ explicação intersubjetiva de autonomia, o ponto de partida é a compreensão de que a autonomia plena, ou seja, a capacidade de desenvolver e seguir uma concepção própria de vida, baseia-se em condiçôes sociais. Assim, em nossa trajetória social, da infância à vida adulta, desenvolvemos a capacidade de confiar em nossos sentimentos e intuiçóes, defender nossas crenças e considerar nossos projetos e realizaçóes válidos. Anderson e Honneth (2005, p. 130) explicam que ninguém empreende tal viagem só, pois somos todos vulneráveis, em cada momento do percurso, a injustiças que solapam nossa autonomia, náo apenas as que produzem carências materiais, mas também aquelas que rompem relaçóes sociais necessárias para a autonomia.

A concepção que defendemos se apoia na noção de que a autonomia da pessoa é 'vulnerável a rupturas em suas relações com os outros'. Uma maneira consistente de pensar esse problema é colocar a vulnerabilidade social dos agentes na dependência do apoio que encontram durante a vida de relaçóes de reconhecimento. Anderson e Honneth (2005, p. 131) defendem a ideia central de que as competências do agente, aquelas que compreendem a autonomia, requerem dele a capacidade de sustentar certas atitudes com relação a si mesmo (em particular, autoconfiança, autorrespeito e autoestima) e que essas autoconcepções, afetivamente carregadas (ou "relaçôes práticas consigo mesmo", em linguagem hegeliana), dependem, por sua vez, das atitudes de apoio de outros. Na leitura que Honneth (2003) realiza da tradição de Hegel e de George Herbert Mead (1950), esses três modos de se "relacionar praticamente consigo mesmo" são adquiridos e mantidos somente através do reconhecimento por parte daqueles que também reconhecemos.

Nesse contexto, autoconfiança, autorrespeito e autoestima não são crenças nem estados emocionais, mas propriedades emergentes de um processo dinâmico no qual indivíduos se experimentam como possuidores de determinado status: objeto de preocupação por parte de outros, agente responsável e alguém que contribui para um projeto compartilhado. Assim, as relaçóes consigo mesmo não são assunto de um ego solitário que reflete sobre si, mas o resultado de um processo 'intersubjetivo' contínuo, no qual a atitude com relação a si emerge no encontro com uma outra atitude com relação a si.

Podemos ver melhor a importância do reconhecimento mútuo se olharmos para eventos e processos que o rompem. Caso, por exemplo, de instituições e práticas que empreendem atitudes de humilhação/difamação e ameaçam a autoestima de indivíduos, tornando difícil (ou até impossível) que eles desenvolvam sentimentos de dignidade e valor. $\mathrm{O}$ surgimento de sentimentos de vergonha e desvalorização ameaça o significado das realizaçôes desses indivíduos. E, sem aquele significado de que aspiraçóes próprias merecem crédito, o agente social vê seu raio de ação se restringir. 
Certamente, é possível manter, psicologicamente, um sentido de autodignidade perante difamaçóes e humilhaçôes. No entanto, é muito mais difícil fazê-lo em tais circunstâncias, além de envolver custos muito elevados, correspondentes ao esforço do agente para se proteger de atitudes negativas ou para buscar subculturas de apoio.

Essa caracterização inicial dos efeitos nocivos que a difamação e a humilhação trazem para a autonomia do indivíduo e de grupos sociais ilustra claramente a importância do ambiente social. As condiçóes para o desenvolvimento de uma vida autônoma estáo intimamente conectadas com relaçóes de reconhecimento mútuo. Na verdade, a autonomia depende dessas relaçóes em três dimensóes importantes (ANDERSON; HONNETH, 2005, p. 131-132): (a) relaçóes legalmente institucionalizadas de respeito universal pela autonomia e pela dignidade das pessoas (centrais para o desenvolvimento do sentimento de autorrespeito); (b) relaçóes íntimas de amor e amizade (centrais para o desenvolvimento do sentimento de autoconfiança); e (c) redes de solidariedade e valor compartilhado, nas quais o mérito (valor) particular de membros de uma comunidade possa ser reconhecido (centrais para o desenvolvimento do sentimento de autoestima). Na próxima seção, vamos continuar com essa abordagem da autonomia orientada pelo reconhecimento, examinando mais de perto cada uma dessas relaçóes consigo mesmo, seus significados para a autonomia, bem como o perfil dos contextos sociais favoráveis à sua emergência.

A metodologia a seguir detalhada é adequada tanto para identificar rupturas nas relaçóes de reconhecimento social, que ameaçam a autonomia, como para apreender experiências bem sucedidas de autorrealização vivencial, em que pessoas idosas, graças a seu esforço próprio e a redes de reconhecimento social, conquistam graus importantes de autonomia intersubjetiva. Em última instância, queremos, também, resgatar experiências de recriação da condição da pessoa idosa em que, apesar de comprometimentos fisiológicos, os agentes conseguem desenvolver visóes positivas de sua vida, conservando entusiasmo e constante atividade até a morte, apesar da organizaçáo da sociedade e do conhecimento sobre o problema conspirarem contra isso.

\section{Autorrespeito, autoconfiança e autoestima}

(1) O objeto do respeito e do 'autorrespeito' pode ser compreendido como a autoridade do agente para levantar e defender pontos de vista próprios, indicando um procedimento de alguém que se vê na mesma posição de outros. Nessa caracterização, o autorrespeito se traduz pela concepção que o agente tem de si mesmo como fonte legítima de razóes e argumentos para a ação. Se alguém não consegue pensar-se como agente que delibera com competência e é coautor de decisóes, como poderia levar a sério seus raciocínios práticos a respeito do que fazer? Logo, aqueles que dispóem de autorrespeito diminuído - com menor senso de autoridade pessoal - têm dificuldades para se considerarem autores plenos de suas vidas. Portanto, sem autorrespeito, a autonomia é prejudicada.

Com a identificação de fatores que diminuem o autorrespeito, podemos destacar, com Anderson e Honneth (2005, p. 132), o que torna a autonomia dos indivíduos vulnerável, suscitando a necessidade de proteção. Sem nenhuma pretensão de fornecer uma lista completa de fatores que diminuem o autorrespeito, não há dúvida que qualquer caracterização incluiria a subordinação, a marginalização e a exclusão. Essas maneiras de negar aos indivíduos a posição social de colegisladores equivalem a mensagens de que não são competentes para tomar decisóes. Caso não contem com recursos internos vigorosos para resistir a tais práticas, dificilmente chegarão a se conceber como pessoas livres e iguais. Assim, a autonomia dos indivíduos é vulnerável, no sentido de sua diminuição à subordinação, marginalização e exclusão.

Ao longo da história política das sociedades, esses tipos de vulnerabilidade transformaram a garantia de direitos individuais em tarefa central de justiça social. A garantia de direitos individuais, através de uma estrutura legal (Constituição) visa a proteger os indivíduos dessas formas de desrespeito. No interior da cultura liberal contemporânea, ser sujeito de direitos tornou-se equivalente a ter autorrespeito como indivíduo completo. A proximidade entre sujeito de direitos e autorrespeito permite precisar a pretensão central da abordagem orientada pelo reconhecimento (ANDERSON; 
HONNETH, 2005, p. 133): é em virtude de padróes de reconhecimento - nesse caso, padrões legalmente institucionalizados - que a relação prática consigo mesmo é assegurada.

$\mathrm{Na}$ abordagem derivada do reconhecimento, o compromisso liberal de proteger os indivíduos de ameaças à autonomia, acarretando um compromisso com a garantia de direitos individuais, adquire ênfase levemente distinta. Em vez de entender que a garantia dos direitos assegura diretamente a autonomia (bloqueando interferências), o enfoque do reconhecimento vê aí um suporte para a autonomia, sob a forma de apoio ao autorrespeito. Esse apoio significa um raio de ação para lutas por reconhecimento e transformaçóes na sociedade decorrentes de tais lutas.

Nos próximos parágrafos, vamos abordar as outras duas relações práticas consigo mesmo: autoconfiança e autoestima. Nos dois casos, a estrutura argumentativa é a mesma discutida em conexão com o caso do autorrespeito (ANDERSON; HONNETH, 2005, p. 133): uma relação prática consigo mesmo é crucialmente importante para a autonomia plena; o desenvolvimento e a manutenção de uma relação prática consigo mesmo dependem de padróes de reconhecimento; e, por isso, a autonomia dos indivíduos é vulnerável a ameaças àqueles padróes. $\mathrm{O}$ compromisso da sociedade com a proteção da autonomia dos indivíduos acarreta um compromisso com a proteção da infraestrutura do reconhecimento: relaçóes mais ou menos institucionalizadas de reconhecimento que suportam não só o autorrespeito, mas, também, a autoconfiança e a autoestima.

(2) Em geral, quando falamos em 'autoconfiança', pensamos em um agente que tem uma relação de confiança com seus próprios sentimentos, desejos e emoçôes. A autoconfiança está vinculada à capacidade de percepção mediada pelo afeto, fazendo com que o sentimento subjetivo se torne, em primeiro lugar, material para deliberação. Adotando procedimento argumentativo paralelo ao do caso do autorrespeito, podemos começar nos indagando a respeito do que ocorre em casos de ruptura? Baseados em vários estudos, Anderson e Honneth (2005, p. 134) assinalam haver forte evidência clínica indicando que várias formas de trauma - como os que resultam de violência física ou tortura
- levam os indivíduos a ver com suspeita seus próprios sentimentos e a desconfiar de seus desejos. A implicação disso para a autonomia é a seguinte: aqueles que perdem essa forma básica de confiança também perdem apoio para conduzir a vida de acordo com suas convicçóes mais básicas. Isso porque não podem mais confiar que seus desejos sejam autenticamente seus.

A autoconfiança é componente vital de nossa autonomia devido à complexidade que enfrentamos ao procurar acessar nossos sentimentos, desejos, medos, arrependimentos etc. Em parte, a importância da autoconfiança provém da dificuldade do trabalho interpretativo necessário à compreensão de si mesmo - e do caráter evasivo dos relatos construídos na perspectiva da primeira pessoa (ANDERSON; HONNETH, 2005, p. 134), provenientes da resistência do agente em revelar suas vivências subjetivas. A fim de evitar rigidez psicológica, é importante adotar uma perspectiva em múltiplas vozes. E compreender que a contribuição da autoconfiança para a autonomia do agente não guarda tanta relação com requisitos de racionalidade e articulação argumentativa, como sugerem algumas concepçóes tradicionais.

Além da flexibilidade para responder adequadamente a mudanças de vida, agentes autônomos demonstram abertura com relação a fontes de identidade e escolha. $\mathrm{O}$ modelo de agente autônomo que surge da perspectiva em múltiplas vozes sobre o caráter do "si mesmo" de uma pessoa sugere não só um agente livre de padrões compulsivos de comportamento, mas também aberto a novos desejos. Anderson e Honneth (2005, p. 134-135) explicam que essa ideia se reflete em uma mudança na concepção psicanalítica de maturidade, deslocando-a da capacidade para controlar seus impulsos internos (ou seja, da força do ego) em direção ao potencial para o diálogo interior, para uma abertura com relação à multiplicidade de vozes interiores e à variedade de relaçóes comunicativas com elas.

Como no caso do autorrespeito, a autoconfiança não é uma realização solitária: depende de relaçóes interpessoais nas quais um agente adquire e sustenta a capacidade de se relacionar dinamicamente com sua vida interior. Para Anderson e Honneth (2005, p. 135), fortes evidências indicam que a autoconfiança emerge, 
especialmente, das relaçóes íntimas. Como vivências subjetivas se caracterizam, muitas vezes, pela ambivalência e pela natureza conflituosa, as dificuldades e os riscos inerentes a uma abertura genuína, típica de uma reflexão e de uma deliberação livre e autônoma, podem se revelar arriscados. A coragem para envolver-se com seus sentimentos mais profundos de modo crítico e aberto é facilitada pela certeza do amor de outros e da autoconfiança que esse amor suporta.

A implicação crucial dessa discussão é que a autonomia do indivíduo também é vulnerável a qualquer coisa que diminua direta ou indiretamente a autoconfiança: violaçôes fortes da intimidade, violências físicas e torturas trazem, diretamente, tanto mal à autoconfiança e à autonomia dos agentes que as sociedades assumem compromissos de proteger os indivíduos, procurando prevenir sua ocorrência ${ }^{5}$. No plano dos efeitos indiretos, cumpre chamar a atenção para os compromissos que a sociedade assume quando trata de proteger as condiçóes de autonomia, defendendo e estimulando os tipos de relações que desenvolvem e reforçam a autoconfiança. Por exemplo, políticas dirigidas à família e a relaçóes de trabalho podem ser encaradas como compromissos de proteger e promover um importante componente das capacidades constitutivas da autonomia.

(3) A autonomia da pessoa também pode ser diminuída por ameaças à sua 'autoestima', configurando um tipo de vulnerabilidade que podemos denominar semântica. As condiçôes para o desenvolvimento de sentimentos de autodignidade e autoestima podem ser abaladas por padróes de humilhação e difamação, que tornam a pessoa menos capaz de se autodeterminar em seus projetos. Essa ameaça potencial à autonomia levanta, por sua vez, questôes adicionais sobre justiça social e garantia de autonomia.
A importância da autoestima para a autonomia pode ser ilustrada resgatando importante aspecto vinculado à autoconfiança. O ponto de partida é a compreensão de que a atividade de autointerpretação, central para que o agente possa refletir com autonomia, pressupóe náo só certo grau de abertura afetiva, mas também recursos 'semânticos'. Isso porque os indivíduos não podem decidir por si mesmos os significados de seus atos (de fala) ${ }^{7}$.

A determinaçáo do significado e do valor das atividades de uma pessoa está, fundamentalmente, enquadrada em um campo simbólico e semântico no qual as relaçóes ocorrem (ANDERSON; HONNETH, 2005, p. 136): alguns se referem a esse campo como "espaço de razôes" (McDowell), outros a "horizonte de significados" (Taylor) e "regime de conhecimento/verdade" (Foucault), ou, ainda, "meios socioculturais de interpretação de necessidades" (Fraser). Para falar desse campo, Habermas (1988, p. 88) usa a expressão "mundo da vida”. Na perspectiva do participante, o mundo da vida é um horizonte feito de pré-compreensão, composto da própria linguagem, das evidências culturais (de onde os agentes retiram modelos explicativos que lhes permitem interpretar as situações), das solidariedades dos grupos (que se constituem em torno de determinados valores) e das competências dos indivíduos socializados.

O caráter inevitavelmente 'avaliativo' desse campo semântico-simbólico traz a implicação crucial para a autonomia. Pois, se os recursos semânticos disponíveis para pensar sobre o modo de vida, a condição social ou a idade de alguém forem negativamente carregados, entấo se torna difícil considerá-lo como digno de valor. Talvez náo impossível, mas, se a pessoa não contar com um poder de resistência e recuperação especialmente forte, apoiado por subcultura e esforço próprio - isto é, se não contar com outras fontes de autoestima -, sua

5 Essa é, por exemplo, uma das motivações do Estatuto do Idoso, promulgado pelo Estado brasileiro. É claro, o Estatuto vai muito além, pois também considera a importância de proteger a autoconfiança da pessoa idosa de efeitos indiretos nocivos, além de tratar de assegurar direitos e participação na sociedade, correspondentes, respectivamente, às dimensões do respeito e da estima social. A análise do documento revela que a ideia de reconhecimento está presente como um de seus pressupostos.

${ }^{6}$ A teoria dos atos de fala trata de integrar, simultaneamente, linguagem e ação. Para Searle (1970, p. 17), a teoria da linguagem é parte da teoria da ação, porque falar é uma forma de comportamento regulada por normas. O ponto de partida da teoria é a descoberta de Austin (1990, p. 29) de que "dizer" algo é "fazer" algo (to speak a language is to perform an action): quando falamos, além de expressarmos um conteúdo objetivo (ou proposicional), realizamos uma ação ao dizer algo. A ação consiste no modo pelo qual fixamos o emprego da frase ou sentença, como afirmação (asserção), promessa, ordem, confissão etc. A unidade de significado e comunicação caracterizada por essa dupla estrutura denominamos ato de fala (SEARLE, 1970, p. 16): a produção ou emissão de uma instância de uma sentença - tipo (genérica ou standard) sob certas condições ou, mais simplesmente, o emprego de uma frase em uma emissão. Os atos de fala têm a estrutura F (p), onde "F" assinala a "força ilocucionária" e "p" o "conteúdo proposicional". Isso qualifica a comunicação humana como empreendimento eminentemente intersubjetivo, pois a compreensão dos significados de nossos atos de fala depende sempre de contextos de uso da linguagem e de emissões de outros agentes como nós. 
forma de vida marginalizada deixa de ser opção genuína (ANDERSON; HONNETH, 2005, p. 136). Quando o modo de vida de uma pessoa não obtém compreensão e é alvo de humilhação e difamação, seguir significativamente esse modo de vida torna-se extremamente difícil.

Em conexão com a autonomia, podemos acrescentar algo mais sobre os efeitos que tal difamaçáo tem sobre o sentido de açâo e efetividade da pessoa. Tratase de uma consideração predominantemente formal (ANDERSON; HONNETH, 2005, p. 137): à medida que falta a quem age o sentimento de que o que faz é significativo, torna-se difícil buscá-lo com sinceridade e entusiasmo. Há, ao menos, uma tensão entre seguir aquele modo de vida e pensar-se como alguém que faz algo com sentido, pois estar capacitado a ver sentido no que se faz está intimamente ligado a realmente fazê-lo. Assim, um ambiente sociocultural hostil em considerar o que alguém faz como significativo é 'desmoralizante'. Pela maneira de abalar a autoestima, padróes sistemáticos de difamação ameaçam não somente a felicidade ou a identidade, mas a ação das pessoas atingidas.

Para o exercício da autonomia, os indivíduos não dependem somente de um ambiente semântico-simbólico que os compromete parcialmente, capacitando autointerpretaçóes ricas. Além disso, os indivíduos também são vulneráveis a ambientes simbólico-semânticos hostis e difamadores que assediam ou limitam sua ação autônoma. Por conseguinte, uma concepção de justiça social que se compromete seriamente em proteger a autonomia dos indivíduos deve incluir uma proteção contra ameaças de difamação.

Chegamos, assim, ao esboço de um modelo de autonomia derivado do reconhecimento social, em que a autonomia representa uma propriedade emergente de indivíduos enquanto dotados de certas capacidades/aptidóes socialmente situadas. Esse enfoque teórico torna a articulação e a teorização entre o nexo mutualidade (reciprocidade) e habilitação individual mais simples e diretas.

A autonomia plena - a capacidade real e efetiva de desenvolver e buscar sua concepção própria de vida digna - é facilitada por relaçóes consigo mesmo (autorrespeito, autoconfiança e autoestima), que estão, por sua vez, conectadas com redes de reconhecimento social. Entendemos que a participação nessas redes é fundamental para que a pessoa idosa possa dispor de meios normativos para enfrentar condiçóes de vulnerabilidade derivadas de um contexto social que tende a desvalorizar seu modo de vida.

No entanto, é importante não esquecer que autoconfiança, autorrespeito e autoestima continuam sendo realizações mais ou menos frágeis e vulneráveis a várias formas de violação, injúria e difamação, tornando a proteção dos contextos sociais em que emergem uma questão central de justiça, envolvendo a sociedade como um todo.

\section{Saúde, vulnerabilidade e reconhecimento da pessoa idosa}

O caminho para legitimar a compreensão da autonomia intersubjetiva do idoso como modelo de orientaçáo para instituição de políticas públicas em nossa sociedade pode começar pela discussão dos parâmetros teórico-metodológicos do reconhecimento social na reflexão das práticas de saúde de profissionais nos serviços de saúde. Na prática da saúde coletiva, o uso corrente, no sentido liberal, do conceito de autonomia influencia as políticas públicas voltadas para a assistência integrada, baseada na perspectiva da prevenção e recuperação das doenças na idade madura.

Tal orientação privilegia cuidados centrados no indivíduo, deixando em segundo plano a vida normativa e o reconhecimento dos idosos na sociedade. Além disso, os serviços de saúde se organizam por especialidades, fragmentando os cuidados. Entendemos que a concepção de autonomia intersubjetiva, além de colocar em foco a questão da saúde psicossocial, pode, também, contribuir para repensar, de modo interdisciplinar, o problema da saúde integral da pessoa idosa.

Podemos nos aproximar dessa compreensão acrescentando à discussão elementos conceituais de Canguilhem (1979) a respeito de vida, saúde e doença (PUTTINI; PEREIRA JUNIOR, 2007; PUTTINI; PEREIRA JUNIOR; OLIVEIRA, 2010; ALMEIDA FILHO, 2000). O autor entende que vida é uma atividade dinâmica de interaçáo com o meio, ao mesmo 
tempo normativa e polarizada entre saúde e doença, implicando o organismo como um todo, com funçóes interdependentes e ritmos harmonizados. A vida não é indiferente com relação às condiçóes de seu desenvolvimento, já que reage dinamicamente ao meio. Além disso, é uma atividade normativa em processo no todo vivo: constitui uma normatividade biológica que institui autonomamente suas próprias normas em função do meio.

Nesse contexto, a saúde pode ser compreendida como uma norma de autonomia de indivíduos e grupos com relação a seu meio de vida. Em vez de adaptação, saúde é ser normal no sentido normativo, quer dizer, poder viver e agir no meio em que se evolui, mas também comportar-se normativamente instituindo novas normas de regulação do meio. A doença consiste em um 'esforço da natureza no homem para obter novo equilíbrio', sendo realmente outro comportamento da vida. Pois o estado de doença impóe ao homem outra vida, mesmo no sentido biológico do termo, e ao organismo a modificação de seus comportamentos anteriores.

A doença é um fenômeno qualitativo anormal e o estado de saúde mantém a pessoa na inconsciência de seu corpo, ou seja, 'a saúde é a inocência orgânica'. A definição de doença é aquela dada pelo doente, por sua consciência, e não pelo médico, pois é o doente que não se sente normal, não idêntico ao seu passado. Saúde e doença podem existir simultaneamente em uma pessoa, quando há patologia, mas a pessoa se considera em estado de saúde e, inversamente, quando não há patologia, mas a pessoa se considera doente.

É importante enfatizar que o termo normal corresponde a uma norma, entendido tanto como o que constitui uma média como o que deve ser. Canguilhem (1979) sustenta haver uma diferença qualitativa entre normal e patológico, pois um fato patológico só pode ser apreendido considerando o organismo como um todo. Por um lado, porque o organismo forma um todo, sendo que todas as suas funções se modificam. Por outro, porque o patológico só se expressa de modo consciente na pessoa, constituindo-se para o doente em nova experiência.

Como refletir nesse contexto sobre a vulnerabilidade da pessoa idosa?
A resposta parece estar em uma reflexão que reúne dois pontos de vista: pensar a vulnerabilidade do idoso, por um lado, do prisma de um questionamento ontológico e, por outro, procurando considerá-la pelo que de fato é. Não só como limitação, mas também pelo que encerra de potencial afirmativo.

Toda a dificuldade consiste em manter esses dois aspectos, ontológico e empírico, a fim de, simultaneamente, evitar a abstração sem consistência e a simples constância do fato. Inspirando-se em Canguilhem (1979), Le Blanc (2007) sugere que a questão está na capacidade do ser vivo, do homem, de inventar normas, sem as quais não saberia assegurar sua sobrevivência, na dimensão da normatividade da vida. Tese ontológica que sustenta a vida como potência realizada pela produção incessante de normas pelos homens e não pela submissão às já existentes.

Isso pressupóe uma vulnerabilidade do homem, marca de seu caráter finito, solidária de seu ser dependente do meio e de outros homens e, portanto, sempre em perigo. Mas, igualmente capacitado para resistir e recompor com outros uma força de expansão. Nesse sentido, podemos falar de uma vulnerabilidade ontológica, a qual o homem está sempre exposto. Todavia, reduzir a vulnerabilidade social, que pode se traduzir em nossas sociedades pelo desrespeito e pela desvalorização de um modo de vida, como o dos idosos, à vulnerabilidade ontológica é, na verdade, recusar-se a pensá-la e esconder a patologia social, legitimando-a e naturalizando-a.

Para Le Blanc (2007), a vida cotidiana consiste em um jogo, uma busca com as normas, um jogo de "se desvincular no ato mesmo de se vincular a elas". Esse jogo constitui o eu que experimenta sua vulnerabilidade e passividade sob a espécie de um desejo de autonomia que só se realiza intersubjetivamente. Normalidade e a normatividade são, portanto, dois aspectos solidários que não permitem reduzir a vida ordinária à sujeição às normas.

Que operaçóes de qualificação e de desqualificação caracterizam as vidas cotidianas? Como entender a vulnerabilidade socialmente produzida?

A vulnerabilidade social aparece no processo ou jogo pelo qual os indivíduos se constituem quando estes 
se encontram tolhidos em suas condiçóes de participação na representação e na construção das normas, como sugere o paradigma do reconhecimento. Não pode ser verdadeiramente identificada por critérios objetivos, pois é um sentimento que o indivíduo experimenta abalando sua humanidade. Esse sentimento não pode, todavia, ser reduzido a uma maneira de ser no mundo de um sujeito, pois expressa relação social constitutiva da identidade.

O paradigma do reconhecimento social indica que o próprio processo de constituição do eu expóe o homem à vulnerabilidade. Baseando-se, simultaneamente, em condiçóes objetivas e sociais de inscrição do homem no mundo, bem como em seu potencial normativo, o processo que conduz à vulnerabilidade é o contrário do que sustenta com autonomia intersubjetiva a vida cotidiana. Enquanto esta vincula o homem a suas capacidades por meio de normas sociais que asseguram visibilidade e compreensibilidade à vida, a vulnerabilidade tende a desvincular o homem de suas capacidades por meio da erosão das normas sociais, tornando as capacidades opacas e pouco utilizáveis.

Como orientar uma prática de cuidados com relação à vulnerabilidade social?

A crítica envolve o compromisso com cuidados e a orientação com vistas a uma política. $\mathrm{O}$ cuidado se baseia na necessidade do vulnerável de ver seu potencial normativo reforçado por meio de políticas que organizem apoio social, sem o qual nenhum humano pode sentir-se capaz de agir e falar. Isso implica reconhecer a multiplicidade das maneiras de viver e ser humano, diferentemente de modelos que buscam a mera adaptação.

É nesse contexto que o paradigma do reconhecimento social e a concepção intersubjetiva de autonomia podem contribuir. Pois permitem compreender a importância fundamental das três esferas do reconhecimento, afeto-amor, respeito e estima na experimentação de modos inéditos de instituição normativa para enfrentar a fragilização do humano. Cuidar dos vulneráveis significa fazer um esforço para desconstruir a vulnerabilidade, mas também significa tornar visível o homem precário como homem genérico, e não só como homem específico.

A vulnerabilidade social é completamente distinta da ontológica, em que a vida surge, por si só, como frágil: ao tornar-se natural, a vulnerabilidade social revela uma forma de violência socialmente produzida, que coloca para a crítica o problema de como desmontar as formas ideológicas de justificação, que naturalizam a fragilidade. Por isso, em sua vertente construtiva, Le Blanc (2007) se orienta pela redescoberta da palavra para instituir "uma política das açóes criadoras das vidas ordinárias".

\section{Conclusão}

Quais elementos recomendam a utilização do conceito de "autonomia intersubjetiva" na orientação dos cuidados à pessoa idosa? O pressuposto parece ser a importância para a saúde integral da pessoa idosa de poder participar da vida normativa em redes de relaçóes sociais valorativas de afeto, amizade, estima social, reconhecimento de direitos e responsabilidades. Apesar de não dispormos de muitas pesquisas orientadas pelo paradigma do reconhecimento, é muito razoável supor que a falta de participação e o rompimento da normatividade nessas redes de relaçóes sociais que sustentam a vida moral intersubjetiva - por atitudes de desvalorização (difamação ou humilhação), desrespeito (subordinação, marginalização e exclusão) e por violências (traumas) - contribua para fenômenos de isolamento, desorientação mental, fragilização e para o surgimento de doenças entre a população idosa. Além de contribuírem para a manutenção da saúde das pessoas idosas, políticas públicas orientadas pelo paradigma do reconhecimento social podem reforçar o sentimento de dignidade, a solidariedade e a justiça social. 


\section{Referências}

ALMEIDAFILHO,N.Oconceito desaúde:ponto-cego daepidemiologia? Revista Brasileira de Epidemiologia, São Paulo, v.3, n.1-3, p. 4-20, 2000. Disponível em: <http://www.scielo.br/scielo.php? script=sci_ arttext\&pid=S1415-790X20 00000100002\&lng=en\&nrm=iso >. Acesso em: 27 jul 2012.

ANDERSON, J. ; HONNETH, A. Autonomy, Vulnerability Recognition and Justice. In: CHRISTMAN, J.; ANDERSON, J. (eds.). Autonomy and the Challenges to Liberalism. New York: Cambridge University Press, 2005. p. 127-149.

ATCHLEY, R.; SELTZER, M. The Sociology of Ageing: Selected Readings. Belmont, California: Wadsworth, 1976.

AUSTIN, J. Quando dizer éfazer. Porto Alegre, Artes Médicas, 1990.

CANGUILHEM, G. Le normal et le pathologique. Paris: Presses Universitaires de France, 1979.

CLARK, R.; SPENGLER, J. The Economics of Individual and Population Ageing. Cambridge: Cambridge University Press, 1980.

EAKIN, J. et al. Towards a critical social science perspective on health promotion research. Health Promotion International, Oxford, v. 11, n. 2, p. 157-165, 1996

FRASER, N. Social Justice in the Age of Identity Politics: redistribution, recognition, and participation. The Tanner Lectures on Human Values. Stanford: Stanford University, 1996.

HABERMAS, J. Le discours philosophique de la modernité. Paris, Gallimard, 1988.

HONNETH, A. Luta por reconhecimento: a gramática moral dos conflitos sociais. São Paulo: Ed. 34, 2003.

HORKHEIMER, M. Teoria tradicional e teoria crítica. In: BENJAMIN, W. et al. Textos Escolhidos. São Paulo: Abril, 1975. p. 125-162.

LE BLANC, G. Vies ordinaries, vies précaires. Paris: Seuil, 2007.

MEAD, G. H. Mind, Self and Society. Chicago: The University of Chicago Press, 1950

NEDELSKY, J. Reconceiving Autonomy: Sources, Thoughts, and Possibilities. Yale Journal of Law, New Haven, v.1, n. 7, spring 1989.
PUTTINI, R. F.; PEREIRA JUNIOR, A. Além do mecanicismo e do vitalismo: a "normatividade da vida" em Georges Canguilhem. Physis: Revista de Saúde Coletiva, Rio de Janeiro, v. 17, n.3, p. 451-464, 2007. Disponível em: <http://www.scielo.br/scielo. php?script=sci_arttext\&pid=S0103-73312007000300003\&lng=pt \&nrm=iso>. Acesso em: 27 jul 2012.

PUTTINI, R. F.; PEREIRA JUNIOR, A.; OLIVEIRA, L. R. Modelos explicativos em saúde coletiva: abordagem biopsicossocial e auto-organização. Physis: Revista de Saúde Coletiva, Rio de Janeiro, v. 20, n.3, p. 753-767, 2010. Disponível em: <http://www. scielo.br/scielo.php?script=sci_arttext\&pid=S0103-733120100 00300004\&lng=en\&nrm=iso >. Acesso em: 27 jul 2012.

SCHUMACHER, A. A. et al. Reconhecimento social e autonomia intersubjetiva da pessoa idosa. In: INTERNATIONAL CONGRESS OF QUALITATIVE INQUIRY, 5., 2009, Urbana. Urbana: University of Illinois at Urbana Champaign, 2009.

SEARLE. J. R. Speech acts. Cambridge, Cambridge University Press, 1970.

STEARNS, P. N. Old Age in European Society. London: Croom Helm, 1977.

TAYLOR, C. Multiculturalism and "The Politics of Difference". Princeton: Princeton University Press, 1992.

TESSER, C. D. Medicalização social (I): o excessivo sucesso do epistemicídio moderno na saúde. Interface, Botucatu, v.10, n. 19, p. 61-76, 2006. Disponível em: <http://www.scielo.br/scielo. php?script=sci_arttext $\&$ pid $=$ S1414-32832006000100005\&lng $=p$ t\&nrm=iso>. Acesso em: 27 jul 2012.

TIBBITTS, C. Handbook of Social Gerontology. Chicago: University of Chicago Press, 1960.

TOWNSEND, P. The Structured Dependency of the Elderly: A Creation of Social Policy in the Twentieth Century. Ageing and society, Cambridge, v. 1, i. 1, p. 5-28, jan. 1981.

WAITZKIN, H. A Critical Theory of Medical Discourse: Ideology, Social Control, and the Processing of Social Context in Medical Encounters. Journal of Health and Social Behavior, Thousand Oaks, v. 30, p. 220-239, 1989.

Recebido para publicação em Julho/2012

Versão final em Maio/2013

Conflito de interesse: não houve

suporte financeiro: inexistente 